$\xi=-1$

\title{
Construction Material Management through Inventory Control Techniques
}

\author{
V. RathinaKumar ${ }^{1}$, K. LalithaPriya ${ }^{2}$, Prasanna kumar.I ${ }^{3}$, C. Ravekumar ${ }^{4}$ \\ ${ }^{I}$ Assistant Professor, School of Civil Engineering, SASTRA Deemed -to be-University, Thanjavur (Dt) \\ ${ }^{2}$ Assistant Professor, Mookambigai College of Engineering, Kalamavur, Pudukottai (Dt) \\ ${ }^{3}$ Student - M.Tech in Construction Engineering and Management(Integrated), \\ SASTRA Deemed -to be-University, Thanjavur(Dt) \\ ${ }^{4}$ Student - B.Tech in Civil Engineering, SASTRA Deemed -to be-University, Thanjavur(Dt) \\ *Corresponding Author Email: ${ }^{1}$ rathinakumar@civil.sastra.edu, ${ }^{2}$ lalithapriya2612@gmail.com \\ ${ }^{3}$ i.prasanna1996@gmail.com, ${ }^{4}$ rave17031998@gmail.com
}

\begin{abstract}
Objectives: A research has shown that the construction materials account for more than $55 \%-60 \%$ of the total expenditure of a project. Efficient material planning plays a major role in the successful handing over of a project within the estimated cost and schedule. Methods: This paper mainly focuses on materials planning and inventory control as these are the major aspects of material management. $\mathrm{S}$-curve analysis is performed to measure the fluctuation between estimated materials cost and market materials cost. The major reasons for this are identified by interviewing engineers and contractors. Inventory control techniques such as ABC classification as well as EOQ analysis are conducted. Findings: The result of the S-curve analysis show that the actual materials cost is higher than the planned materials cost in most cases. ABC and EOQ analysis are applied to maintain sufficient stock in inventory and any given point of time, to protect the materials in the inventory against damages, to reduce inventory holding costs, to overcome stock-out problems and to maintain the inventory in an optimal level. Sensitivity check is applied to the results of EOQ analysis. The stock-out of A class and B class material problems faced in the construction site can be reduced by the application of ABC classification and BOQ analysis. The total expenditure of inventory is less after the adoption of these simple inventory control techniques. Conclusion: Instead of using costly software for inventory management, the engineers and contractors may use these simple inventory control techniques which are equally beneficial and economical.
\end{abstract}

Keywords: Material management, Inventory control, S-curve analysis, ABC classification, EOQ analysis.

\section{Introduction}

Material management is one of the influential aspects of construction projects as the materials account for about $55 \%-60 \%$ of the total construction cost. Efficient material planning is the key to successful construction projects. Material management is stated as the process of providing proper quantity and quality of proper materials at the appropriate place in the specified time. The process of planning of materials, procurement of materials, inventory control, storage of materials, handling and transportation, standardizing the material comes under material management. Often construction projects suffer from cost overrun and time overdue. These issues can be avoided by properly implementing material management which ensures the timely flow of materials to the job site which in turn increases the labour productivity and thus reduces the cost of the project. Exercising control over the material cost can effectively reduce the cost of the project because of the reason mentioned before. Material planning and inventory control are the two most important aspects of material management.

Material planning defined as the determination of the requirement that fulfills the construction need under economic investment policies. Material planning comprises of activities such as identifying, quantifying and scheduling the materials required for the project. In this paper, material planning is reviewed through Scurve analysis and the main causes for fluctuation in planned materials cost and actual materials cost are identified through interviews with contractors and engineers. The goal of inventory management is to maintain an adequate supply of materials to meet an expected demand pattern for a given financial investment. Proper inventory management is necessary to maintain the materials in good and usable condition. Also, in this paper, ABC classification is used to categorize the materials based on their importance and value, so that the materials representing a major portion of the cost can be managed with extra care. Too large quantity in the inventory leads to higher holding cost while too less quantity in the inventory leads to more number of orders thus resulting in higher ordering cost. EOQ analysis is used to balance the inventory holding cost and ordering cost and to reduce the expenditure of the former. Some of the research works on this topic are useful to understand the process and problems in construction materials management, Hemishkumar Patel, et al. ${ }^{1}$ explores the factors affecting materials management and inventory management. Relative importance index (RII) and Importance index techniques are used to rank the factors.

The Frequency of occurrence and severity of the factors were also considered. Design errors and inadequate details in drawings were 
found to be most important factors by both the methods. P. Lenin, et al. ${ }^{2}$ analyses the effect of improper materials management on cost of the construction projects. The topmost reasons for the cost overrun in construction project is said to be client and contractor's issue, issue's due to design, labour, equipment, storage and market. Carlos H. Caldas, et al. ${ }^{3}$ identifies the current and emerging practices for management of materials in the construction industry. It was recognized that the use of technology has been increased in the construction industry and the contractors and owners stretch more importance to supplier relationship. It is also identified that most of the organizations suffer from non-conformism and defects frequently. Dinesh Dhoka, et al. ${ }^{5}$ explores the use of $\mathrm{ABC}$ classification for optimizing the inventory. This study chiefly focuses to check whether some assumptions of $\mathrm{ABC}$ analysis are taken for granted. It is found that improperly done $\mathrm{ABC}$ analysis lead to serious inventory management issues. Narimah Kasim, et al. ${ }^{7}$ analyses how ICT tools can be used as a solution for materials management issues in construction industry. Most important problems in the construction material management are identified and ICT tools are suggested to overcome these problems. Microsoft office is found to be extensively used by contractors and engineers for materials management. Bar coding and RFID technology are hardly adopted by organizations because of its high cost. Jongchul Song, et al. ${ }^{8}$ analyses the feasibility of using RFID tags for trailing the location of construction materials in the work area. A mathematical model was designed to check the technical feasibility of this method, the materials location is known with the help of proximity read from a discrete range from the site, where the site is considered as the grid.Field performance was measured and compared with the theoretical positional accuracy obtained from the discrete formulation. Nawaj Kalim Hannure, et al. ${ }^{9}$ compares the traditional materials management techniques with materials management using ICT tools. Effect of ICT tools on materials management in construction industry was analyzed and the variance in traditional materials management method and materials management with ICT tools was computed. This study reveals that by adopting ICT tools for materials management, the percentage cost of materials saved was $6.35 \%$ without considering the implementation cost.

\section{Methodology}

\subsection{Case Study}

An ongoing project of the residential apartment with the Stilt+4 floor was taken for the case study for the research work. The residential apartment has the built-up area of 3224.20 square feet with three dwellings per floor.

\subsection{S-Curve Analysis}

The S-curve is stated as "a display of cumulative costs, labour hours or other quantities plotted against time or other parameters". It is a form of numerical theory, which represent the usage of materials over the stipulated time of the project. The curve explains the comparison of the actual time and expenditure components vs. the estimated costs and time allotted for specific resources. It is used to track the growth in the project. In this research we use S-Curve to analyse the comparison of the planned material's cost and the actual material's cost. The S-curve analysis is carried out for some of the most important construction materials such as Cement, Steel and Bricks.

The similarity between planned and actual material cost of Cement, Steel and Brick in the construction of a residential apartment is shown in Table 1, Table 2, Table 3 respectively. It is very clear from the graphs that the actual materials cost is higher than the planned materials cost. The Cost Performance Index is less than 1 for all the 3 materials states that there is a cost teeming in the project. Though this is a small apartment project, the materials management aspect is same for small and big projects.

Table 1: Cost Performance for Cement

\begin{tabular}{|c|c|c|c|c|c|}
\hline S1 No & Floor & Planned cost (INR) & Actual cost (INR) & Cost variance (INR) & Cost Performance Index \\
\hline 1 & Stilt & 425655 & 468220 & 42565 & 0.909 \\
\hline 2 & First & 359640 & 397403 & 37763 & 0.905 \\
\hline 3 & Second & 359640 & 396324 & 36684 & \\
\hline 4 & Third & 359640 & 397523 & 37943 & 0.907 \\
\hline 5 & Fourth & 359640 & 397762 & 38122 & 0.905 \\
\hline
\end{tabular}

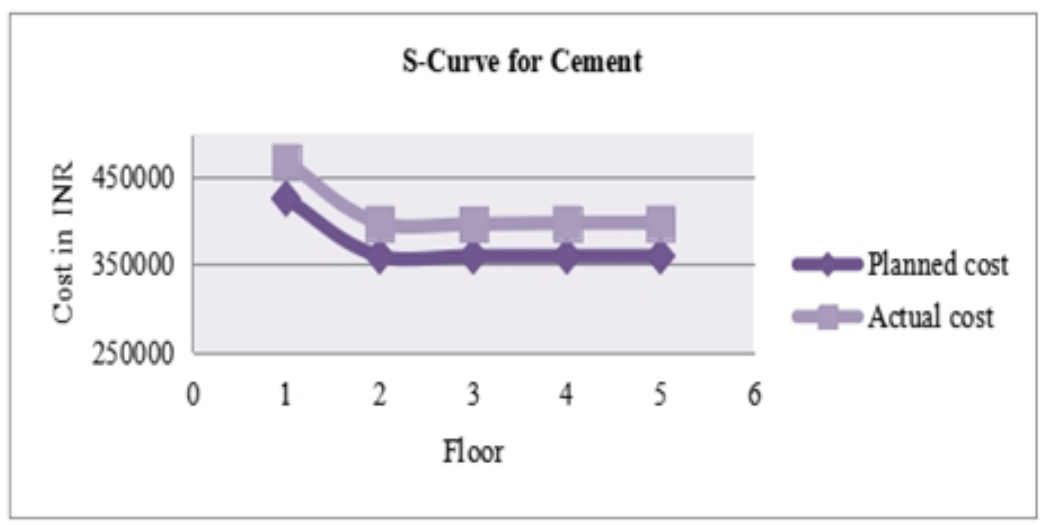

Fig. 1: S-Curve Analysis for Cement

Table 2: Cost Performance Index for Steel

\begin{tabular}{|c|c|c|c|c|c|}
\hline $\begin{array}{c}\text { Sl } \\
\text { No }\end{array}$ & Floor & Planned cost (INR) & Actual cost (INR) & Cost variance (INR) & Cost Performance Index \\
\hline 1 & Stilt & 384230 & 391914 & 7684 & 0.980 \\
\hline 2 & First & 207477 & 211420 & 3943 & 0.981 \\
\hline 3 & Second & 207477 & 211523 & 4046 & 0.981 \\
\hline 4 & Third & 207477 & 211502 & 4025 & 0.981 \\
\hline 5 & Fourth & 207477 & 211586 & 4109 & 0.980 \\
\hline
\end{tabular}




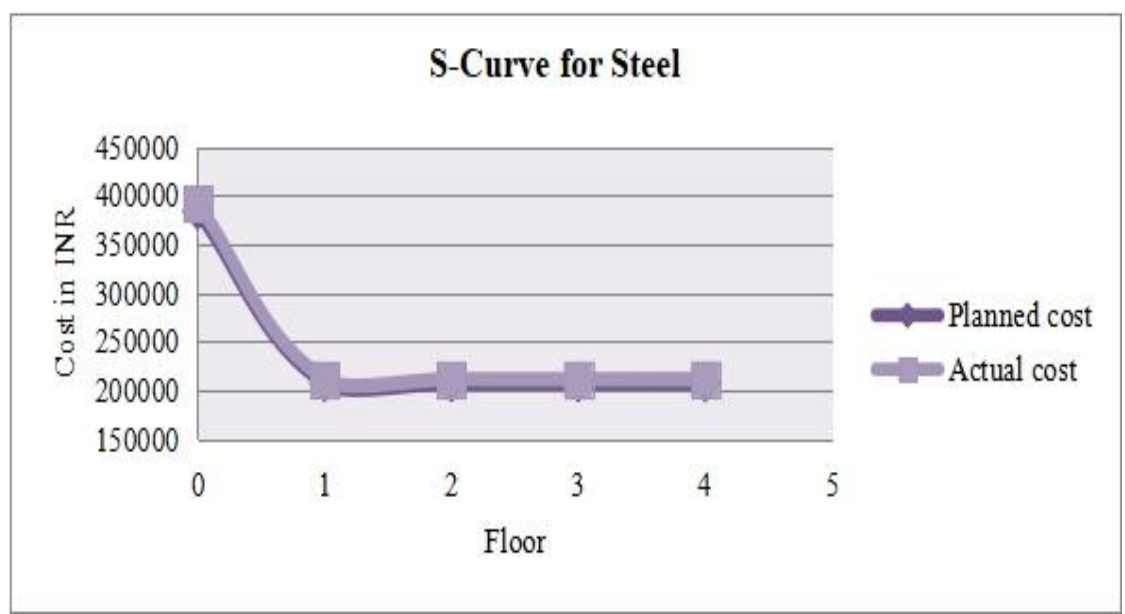

Fig. 2: S-Curve Analysis For Steel

Table 3: Cost Performance Index For Bricks

\begin{tabular}{|c|c|c|c|c|c|}
\hline S1 No & Floor & Planned cost (INR) & Actual cost (INR) & Cost variance (INR) & Cost Performance Index \\
\hline 1 & Stilt & 47888 & 54592 & 6704 & 0.877 \\
\hline 2 & First & 270142 & 302560 & 32418 & 0.893 \\
\hline 3 & Second & 270142 & 304720 & 34578 & 0.887 \\
\hline 4 & Third & 270142 & 304990 & 34848 & 0.885 \\
\hline 5 & Fourth & 270142 & 305260 & 35118 & \\
\hline
\end{tabular}

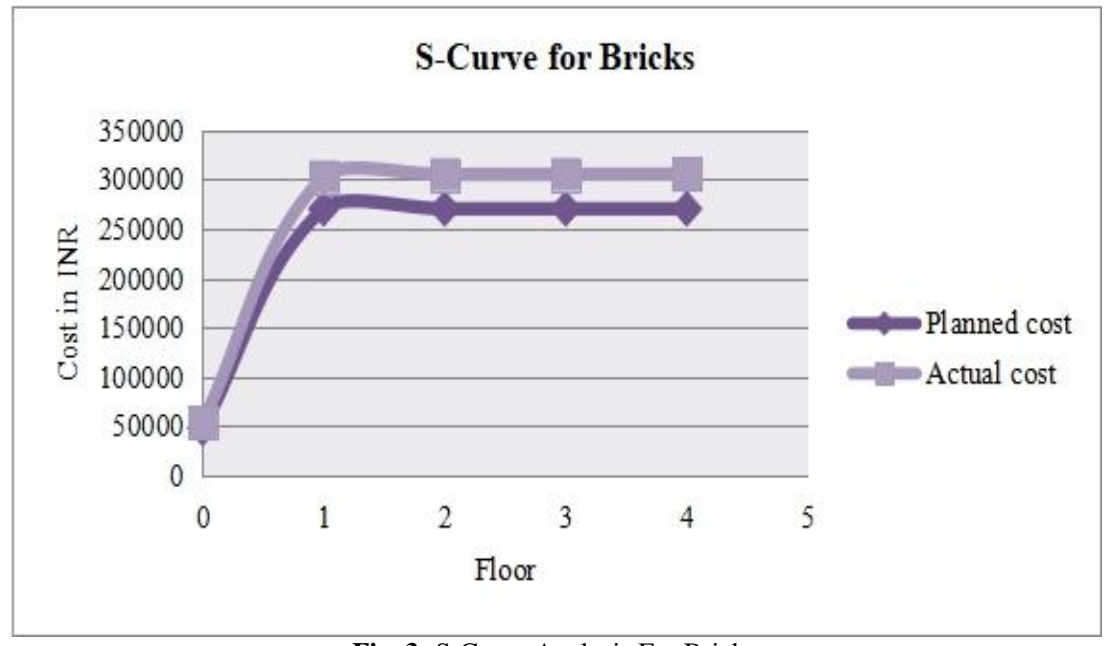

Fig. 3: S-Curve Analysis For Bricks

\subsection{Reasons for Cost Variance}

The project cost can be contained by recognizing the main causes for cost variance and taking remedial actions according to that. To identify the main causes for cost variance in materials management, interviews have been conducted with experienced personnel, particularly engineers and contractors. The main reasons affecting the cost variance, which was obtained through the extensive interviewing, are listed below:

- Poor scheduling and estimation of materials

- Poor forecasting of field conditions, weather, and events in future

- Poor market prediction

- Scarcity of materials in the market

- Changes in materials condition during transportation

- Materials quality variance from specification

- Damages of materials occurred during storage

- Inefficient utilization and wrong utilization of materials

- Deviations from original plan or drawing due to client intervention

- Changes in economic and legal conditions

\subsection{ABC Classification of Materials}

An important aspect is to classify the items based on the importance and its value. Categorizing the inventory permits us to identify the inventory, which requires due attention and proper management. It also prevents it aids in exact utilization of resources reducing wastage. $\mathrm{ABC}$ analysis is the basis on which materials are managed and helps specify stocking and helps determining the interval of inventory checks. It is an analytical technique of controlling different items of inventory. ABC classification is based on Pareto's law which states that a small percentage of items' accounts for a large percentage of value. In this technique all the materials are classified under 3 categories A, $\mathrm{B}$ and $\mathrm{C}$. In $\mathrm{ABC}$ classification, the materials are classified as

- A class material - $20 \%$ materials account for $70 \%$ of money value.

- B class materials - $30 \%$ materials account for $25 \%$ of money value.

- C class materials - 50\% materials account for $5 \%$ of money value.

The items in the inventory are classified based on factors such as investment, value of material used and nature of inventory items. 
The following procedure is adopted to perform $\mathrm{ABC}$ classification:

- Different materials required for the construction project are identified and their estimated quantities worked out.

- The unit rates of materials are estimated.

- The usage values for each of the materials are obtained by multiplying by the estimated quantities and their unit rates.

- These values are converted into percentage of total annual usage or total project cost.

- The percentage usage cost for each of the materials is arranged in the descending order of their ranking, starting with first rank, i.e., highest to lowest usage value.

\subsection{EOQ Analysis}

The vital categories of inventory costs are ordering costs and holding costs. Ordering costs incurred by obtaining list such as communicating order, transportation costs, costs for supplier selection etc. Holding costs represent the costs incurred on holding the list. It includes storage costs, spoilage costs, insurance, taxes etc. Ordering costs and Carrying costs are exactly opposite to each other. To minimize the carrying costs small orders should be placed but that in turn increase the ordering costs and vice versa. EOQ model helps to decrease the total inventory expenditure. The Economic Order Quantity (EOQ) is defined as an inventory related model which is used to obtain the optimal quantity that can be purchased to reduce the cost of both the carrying inventory and the processing of purchase orders.

The formula used to calculate the optimum quantity is

$$
\mathrm{Q}=\sqrt{\frac{(2 * \mathbf{0} * \mathbf{D})}{(\mathbf{I} * \mathbf{C})}}
$$

$\mathrm{Q}$ - Order quantity; number of units per order

$\mathrm{O}$ - Ordering cost; INR/order

$\mathrm{D}$ - Rate of demand

I - Inventory carrying cost

$\mathrm{C}$ - Unit cost of the material

Here the EOQ analysis is carried out for the A-class materials required for the construction of a $\mathrm{G}+4$ residential apartment. The EOQ analysis is shown here.

Table 4: EOQ analysis of A-class materials

\begin{tabular}{|c|c|c|c|c|}
\hline Sl. No & Quantity Required & EOQ & No. of Orders & Frequency of Ordering \\
\hline 1 & 4603 bags & 165 & 28 & 13 \\
\hline 2 & $32 \mathrm{~T}$ & 1.5 & 22 & 16 \\
\hline 3 & $192898 \mathrm{nos}$ & 8015 & 25 & 14 \\
\hline 4 & $25823 \mathrm{cu} . \mathrm{ft}$ & 833 & 31 & 10 \\
\hline 5 & $10930 \mathrm{cu} . \mathrm{ft}$ & 500 & 22 & 16 \\
\hline
\end{tabular}

\subsection{Sensitivity Analysis}

Sensitivity analysis is an approach that helps to find out how sensitive an output is to any change in one or more inputs. It is often used to compare different scenarios and their outcome is based on changing inputs. It is advantageous because it helps to know how dependent the output value is on each input value. The procedure for conducting sensitivity analysis is as follows:

- Find the primary output value using primary input values.

- Find the new output value by changing an input value while keeping all other input values constant.

- Calculate the percentage change in output value and percentage change in output value.

- Determine the sensitivity by diving percentage change in output by percentage change in input.

In this paper, the sensitivity analysis is done to know how the changes in the values of demand and inventory holding cost affects the output value of EOQ as these input values are more prone to changes.

\section{Results and Discussion}

- The results of the S-Curve analysis prove that there is an fluctuation in cost of planned and actual materials cost. From the graphs the actual materials cost is higher than the planned materials cost. Cost Performance Index is calculated for each material and it supports the results of S-curve analysis by clearly stating that the Cost Performance index is less than 1, which means the project is under cost overrun.

- The reasons for fluctuation in planned and actual materials cost are found to be poor scheduling and estimation, poor prediction of market and field conditions, scarcity of materials, damages occurred due to transportation of the materials and storing in stock yard, issues due to quality, improper planning in material utilization, client intervention, changes in legal and economic conditions. It can be understood from the results that the both internal and external factors contribute to the materials cost overrun
- The materials required for the construction is classified as $\mathrm{A}$, $\mathrm{B}$ and $\mathrm{C}$ class materials by using $\mathrm{ABC}$ classification technique. Aclass materials are cement, steel, bricks, sand and aggregates. Bclass materials are ceramic tiles, emulsion paint, country wood, glazed tiles, teak wood, electrical holders \& fittings, PVC pipes \& accessories, European water closet and paver blocks. The rest of materials come under class $\mathrm{C}$.

- EOQ analysis responses for how much A-class materials such as cement, steel, bricks, sand and aggregates should be ordered and how often the order should be placed to minimize the total inventory cost and to maintain the inventory at an optimal level.

- The result of sensitivity analysis reveals that the sensitivity is 0.3 for $10 \%$ change in demand and sensitivity is 0.42 for $25 \%$ change in inventory holding cost.

- The stock-out of A class and B class material problems faced in the construction site can be reduced by the application of $\mathrm{ABC}$ classification and BOQ analysis.

- The total cost of inventory is found to be less after the application $\mathrm{ABC}$ and EOQ analysis.

\section{Conclusion}

A study indicates that the overall efficiency of the project has increased by $35 \%$ by implementing proper material management. For efficient material management some simple tools are proposed in this project work. S-curve analysis is used to show the fluctuation in planned materials cost and actual materials cost. The main cause for this fluctuation are identified. By focusing on these causes the contractors and engineers can improve their material planning and keep overall project cost under control. ABC classification and EOQ analysis are used to overcome stock out issues and to abate the total inventory cost. Instead of using inflated software for inventory management, the engineers and contractors may use these simple inventory control techniques which are equally advantageous and cost-effective. 


\section{References}

[1] Hemishkumar Patel, Dr. Jayeshkumar Pitroda, Prof. J. J. Bhavsar, "Analysis of Factor Affecting Material Management and Inventory Management: Survey of Construction Firms in Gujarat Region of India”, International Journal of Advanced Research in Engineering, Science \& Management.

[2] P.Lenin, L.Krishnaraj, D.Narendra Prasad , V.R Prasath Kumar, "Analysis of Improper Material Management Affecting Cost in Construction Projects", International Journal for Research in Applied Science and Engineering Technology, 2014 May, p. $486-$ 491.

[3] Carlos H. Caldas, Cindy L. Menches, Pedro M. Reyes, Laure Navarro and Daniel M. Vargas, "Materials Management Practices in the Construction Industry", Practice Periodical on Structural Design and Construction, 2015 Aug.

[4] T.Phani Madhavi, Steve Varghese Mathew, Roy Sasidharan, "Material Management in Construction - A Case study", International journal of Research in Engineering and Technology, 2013 p 400 - 403

[5] Dinesh Dhoka, Dr.Y.Lokeswara Choudary, "ABC Classification for Inventory Optimization", IOSR Journal of Business and Management, 2013 Nov. - Dec, p. 38 - 41.

[6] Eduina Guga, Orjula Mosa, "Inventory Method through EOQ model- A Case study of SHPRESA limited, ALBANIA", International Journal of Economics, Commerce and management, Dec 2015, P 174 -182.

[7] Narimah Kasim, "ICT Implementation for Materials Management in Construction Projects: Case Study", KICEM Journal of Construction Engineering and Project Management, 2011, p. 31 36.

[8] Jongchul Song, Carl T. Haas, Carlos H. Caldas, "Tracking the Location of Materials on Construction Job Sites", Journal of Construction Engineering and Management, 2006 Sep.

[9] Nawaj Kalim Hannure, Sushma Shekhar Kulkarni, "Comparative Study of Traditional Material Management and Material Management with ICT Application", Current Trends in Technology and Science, 2014 June - July, p. $301-307$.

[10] Ibn-Homaid, N. T. (2002). "A comparative evaluation of construction and manufacturing materials management." Int. J. Project Manage., 20(4), 263-270.

[11] Hemanta Doloi, "Cost overruns and failure in project management: Understanding the roles of key stake holders in construction Project", International journal construction engineering and management, March 2013 139(3): 267-279.

[12] Vipulesh Shardeo, "Impact of Inventory Management on Financial Performance of the Firm", IOSR Journal of Business and Management, Apr-2015, p 01-12. 